\title{
Folate malabsorption is associated with down-regulation of folate transporter expression and function at colon basolateral membrane in rats
}

\author{
Nissar Ahmad Wani ${ }^{1}$, Abid Hamid ${ }^{2}$, Krishan Lal Khanduja ${ }^{3}$ and Jyotdeep Kaur ${ }^{1 *}$ \\ ${ }^{1}$ Department of Biochemistry, Postgraduate Institute of Medical Education and Research, Chandigarh 160 012, India \\ ${ }^{2}$ Cancer Pharmacology Division, Indian Institute of Integrative Medicine (IIIM), Council of Scientific and Industrial \\ Research (CSIR), Jammu, Jammu and Kashmir, India \\ ${ }^{3}$ Department of Biophysics, Postgraduate Institute of Medical Education and Research, Chandigarh 160 012, India
}

(Received 17 March 2011 - Revised 3 June 2011 - Accepted 6 June 2011 - First published online 24 August 2011)

\begin{abstract}
Folates, an essential component (important B vitamin) in the human diet, are involved in many metabolic pathways, mainly in carbon transfer reactions such as purine and pyrimidine biosynthesis and amino acid interconversions. Deficiency of this micronutrient leads to the disruption of folate-dependent metabolic pathways that lead to the development of clinical abnormalities ranging from anaemia to growth retardation. Folate deficiency due to alcohol ingestion is quite common, primarily due to malabsorption. The present study dealt with the mechanistic insights of folate malabsorption in colonic basolateral membrane (BLM). Wistar rats ( $n$ 12) were fed $1 \mathrm{~g} / \mathrm{kg}$ body weight per $\mathrm{d}$ ethanol (20\%) solution orally for 3 months and folate transport was studied in the isolated colonic BLM. The folate exit across colon BLM shows characteristics of carrier-mediated process with the major involvement of reduced folate carrier (RFC). The chronic ethanol ingestion decreased the uptake by decreasing the affinity by $46 \%(P<0 \cdot 01)$ and the number of transport molecules by $43 \%(P<0.001)$ at the colon BLM. The decreased uptake was associated with down-regulation of proton-coupled folate transporter (PCFT) and RFC expression at mRNA and protein levels. The extent of decrease was $44 \%(P<0 \cdot 01)$ and $24 \%(P<0 \cdot 05)$ for PCFT and $23 \%(P<0.01)$ and $57 \%(P<0.01)$ for RFC at mRNA and protein levels, respectively. Moreover, folate transporters were associated with lipid rafts (LR) of colon BLM, and chronic alcoholism decreased the association of these transporters with LR.
\end{abstract}

Key words: Rats: Proton-coupled folate transporter: Reduced folate carrier: Alcohol: Lipid rafts: Colon: Folate

Folate is an essential micronutrient, the primary function of which is as a carrier of single-carbon units for the biosynthesis of thymidylate, purines, methionine and glycine ${ }^{(1,2)}$. Maintenance of intracellular folate homeostasis is vitally important; particularly for rapidly replicating cells such as colonic epithelial cells. Indeed, perturbed 1-carbon transfer reactions resulting from folate depletion and disrupted folate metabolism predispose normal colonic epithelial cells to neoplastic transformation through aberrant DNA synthesis, integrity, repair and methylation ${ }^{(3-5)}$. A number of epidemiological and clinical studies linking decreased folate status with risk of colorectal cancer support this. Folate is absorbed in the proximal small intestine after the polyglutamate chain is hydrolysed by glutamate carboxypeptidase II. The hydrolytic step is followed by membrane transport of monoglutamyl folate into cells by folate transporters ${ }^{(6-8)}$. Whereas monoglutamates are the only circulating forms of folate in blood and the only forms of folate that are transported across the cell membrane, once taken up into cells, cellular folate exists primarily as polyglutamates ${ }^{(9)}$. Intracellular folate is converted to polyglutamates by folylpolyglumate synthase ${ }^{(1)}$. The polyglutamylation of cellular folates is a form of metabolic trapping, allowing the retention of folate that would otherwise be lost to efflux from cells ${ }^{(10)}$. In the colon, folate - exogenous as well as synthesised by normal microflora - undergoes the initial step of transport across the brush border membrane (BBM) and then the exit of folate across basolateral membrane (BLM) into portal circulation. The mechanism of absorption of dietary folate in the BBM and BLM of colon has been investigated and the existence of $\mathrm{pH}$-dependent, 4,4'-diisothicyano2,2'-stilbenedisulfonic acid (DIDS)-sensitive, carrier-mediated uptake system has been demonstrated with the involvement of reduced folate carrier (RFC) in the exit of folate out of colonocytes $^{(7,11)}$. However, the role of proton-coupled folate transporter (PCFT) still remains silent.

Abbreviations: BBM, brush border membrane; BLM, basolateral membrane; BLMV, basolateral membrane vesicles; CAM, colon apical membrane; GAPDH, glyceraldehyde 3-phosphate dehydrogenase; LR, lipid rafts; MES, 3-( $N$-morpholino)ethanesulfonic acid; PCFT, proton-coupled folate transporter; rPCFT, rat proton-coupled folate transporter; $\mathrm{rRFC}$, rat reduced folate carrier; RFC, reduced folate carrier.

* Corresponding author: Dr J. Kaur, fax +91 172 2744401/2745078, email jyotdeep2001@yahoo.co.in 
Deficiency of folate is highly prevalent throughout the world and alcohol ingestion has been the major contributor ${ }^{(12,13)}$. Approximately $60-70 \%$ of binge drinkers are folate deficient $^{(14)}$. Regardless of the cause, folate deficiency leads to a variety of clinical abnormalities like megaloblastic anaemia, growth retardation etc., whereas optimisation of folate homeostasis prevents certain disorders like neural tube defects $^{(15)}$. Earlier, we have reported the derangement of PCFT and RFC across colon apical membrane (CAM) and of RFC on intestinal membrane surfaces during chronic alcohol ingestion in $\operatorname{rats}^{(7,13,16-18)}$. However, no studies have been attempted so far to delineate the distribution of folate transporters to lipid microdomains and activity of folate transport system in BLM under conditions of folate malabsorption. For this, the present work was sought to characterise the folate transport across the colon BLM and the role of the folate transporters therein during alcoholism. We used rats as an experimental model of chronic alcoholism based on the published studies demonstrating their resemblance and utility as a model in order to relate to humans on the basis of blood and intestinal alcohol concentration as well as plasma folate levels ${ }^{(18-20)}$. Such mechanistic insights could lead to strategies for deducing folate transport regulation in diverse cellular microenvironments and will be important for designing therapeutic targets involving derangements in folate transport systems in primary absorptive epithelia.

\section{Materials and methods}

\section{Chemicals}

Radiolabelled 5-[ $\left[{ }^{14} \mathrm{C}\right]$-methyltetrahydrofolate, potassium salt with specific activity $24.0 \mathrm{Ci} / \mathrm{mmol}\left(88.8 \times 10^{10} \mathrm{~Bq} / \mathrm{mmol}\right)$ were purchased from Amersham Pharmacia Biotech (Hong Kong). Color brust ${ }^{\mathrm{TM}}$ electrophoresis marker (molecular weight 8000-220 000) was purchased from Sigma Chemical Company (St Louis, MO, USA). Total RNA Extraction Kit was purchased from Taurus Scientific (Cincinnati, OH, USA). Moloney Murine Leukemia Virus RT (RevertAid ${ }^{\mathrm{TM}}$ M-MuLV RT) kit was purchased from the MBI Fermentas, Life Sciences (Glen Burnie, MD, USA). RNA later (RNA stabilisation solution) was obtained from Ambion, Inc. (Austin, TX, USA). Primary antibodies rabbit anti-rat reduced folate carrier (rRFC) and anti-rat protoncoupled folate transporter (rPCFT) polyclonal antibodies were raised in rabbits in our laboratory ${ }^{(7)}$. Horseradish peroxidase labelled goat anti-rabbit-IgG secondary antibodies were purchased from G Biosciences (St Louis, MO, USA). Enhanced Chemiluminescence Detection Kit was purchased from Biological industries Limited (Kibbutz Beit Haemek, Israel). Metal enhanced 3,3'-diaminobenzidine substrate kit was purchased from Thermo Fisher Scientific, Inc. (Rockford, IL, USA). Cryoprotected Lactobacillus casei bacterial strain (MTCC 1423) was purchased from IMTECH (Chandigarh, India).

\section{Animals}

Young adult male albino rats (Wistar strain) weighing 100-150 g (2-3 months old) were obtained from the Institute's Central Animal House. The animals were housed in clean wire mesh cages with controlled temperature $\left(23 \pm 1^{\circ} \mathrm{C}\right)$ and humidity $(45-55 \%)$ and had a $12 \mathrm{~h}$ dark-12 $\mathrm{h}$ light cycle throughout the study. The rats were randomised into two groups of twelve animals each. The rats in group I were given $1 \mathrm{~g}$ ethanol (20\% solution)/kg body weight per d and those in group II received isoenergetic amount of sucrose (36\% solution) orally by Ryle's tube daily for 3 months. The rats were fed ad libitum commercially available pellet diet (Ashirwad Industries, Ropar, India) and water. Animals from both the groups were killed under anaesthesia using sodium pentothal.

The protocol of the study was approved by 'Institutional Animal Ethical Committee' and 'Institutional Biosafety Committee'.

\section{Preparation of colon basolateral membrane vesicles}

Basolateral membrane vesicles (BLMV) from colon was prepared by the self-generating percoll gradient method ${ }^{(21)}$ as described earlier ${ }^{(22)}$. The mucosa was scraped from the proximal colon. The scrapings were homogenised in ice-cold buffer containing $250 \mathrm{~mm}-\mathrm{mannitol}$ and $12 \mathrm{~mm}$-HEPES-Tris, $\mathrm{pH} 7.4$ using a Waring blender for $3 \mathrm{~min}$ and then centrifuged at $2500 \boldsymbol{g}$ for $20 \mathrm{~min}$. The supernatant was then centrifuged at $22000 \mathbf{g}$ for $25 \mathrm{~min}$ and the resulting fluffy layer of the pellet resuspended in the same buffer followed by homogenisation in glass Teflon homogeniser. The resulting homogenate was mixed with percoll at a concentration of $15 \cdot 4 \%$ and centrifuged at $48000 \mathrm{~g}$ for $2 \mathrm{~h}$. A distinct band of BLMV was seen at the upper one-third of the percoll gradient. The band was aspirated by a syringe and suspended in buffer composing $100 \mathrm{~mm}$-mannitol, $100 \mathrm{~mm}-\mathrm{KCl}, 12 \mathrm{mm-HEPES}-$ Tris, $\mathrm{pH} \quad 7 \cdot 4$ and centrifuged at $48000 \mathrm{~g}$ for $20 \mathrm{~min}$. The pellet obtained was resuspended in loading buffer containing $280 \mathrm{~mm}$-mannitol and $20 \mathrm{~mm}$-HEPES-Tris, $\mathrm{pH} 7.4$ and centrifuged at $48000 \mathrm{~g}$ for 20 min twice in order to wash out the residual percoll from membrane preparation. The final pellet representing purified BLMV was suspended in loading buffer (280 mM-mannitol, $20 \mathrm{~mm}$-HEPES-Tris, $\mathrm{pH} 7 \cdot 4$ ) at $5 \mathrm{mg} / \mathrm{ml}$ protein concentration. Purity of the membrane preparations was checked by measuring the specific activities of $\mathrm{Na}^{+}, \mathrm{K}^{+}$-ATPase in BLMV and in original homogenate.

\section{Transport of $5-\left[{ }^{14} \mathrm{C}\right]$-methyltetrahydrofolate}

Uptake studies were performed at $37^{\circ} \mathrm{C}$ using the incubation buffer (100 mm-NaCl, $80 \mathrm{mm-mannitol,} 10 \mathrm{mm-HEPES,} 10 \mathrm{~mm}$ 3-( $N$-morpholino)ethanesulfonic acid (MES), pH 7·0). A quantity of $10 \mu \mathrm{l}$ of vesicles $(50 \mu \mathrm{g}$ protein) was added to the incubation buffer containing $5-\left[{ }^{14} \mathrm{C}\right]$-methyltetrahydrofolate at a concentration as specified. The initial rate of transport was determined by stopping the reaction after $20 \mathrm{~s}$ by adding ice-cold stop solution containing $280 \mathrm{~mm}$-mannitol, $20 \mathrm{~mm}$ HEPES-Tris, pH $7 \cdot 0$ followed by rapid vacuum filtration ${ }^{(18,23)}$

\section{RT-PCR analysis}

Total RNA was isolated from the colon by using total RNA extraction kit and complementary DNA synthesis was carried 
out from the purified and intact total RNA according to the manufacturer's instructions. Expression of RFC, PCFT and glyceraldehyde 3-phosphate dehydrogenase $(G A P D H)$ was evaluated using sequence-specific primers corresponding to the sequence in the open reading frame. PCR mixture $(20 \mu \mathrm{l})$ was prepared in $1 \times$ PCR buffer consisting of $0.6 \mathrm{U}$ of Taq polymerase, $2 \mu \mathrm{M}$ of each primer for $\mathrm{r} G A P D H, \mathrm{rPCFT}$ and $\mathrm{r} R F C$ along with $200 \mu \mathrm{m}$ of each deoxyribonucleotide triphosphate. In optimised PCR, the initial denaturation step was carried out for $2 \mathrm{~min}$ at $95^{\circ} \mathrm{C}$. The denaturation, annealing and elongation steps were carried out, respectively, for $1 \mathrm{~min}$ at $94^{\circ} \mathrm{C}, 45 \mathrm{~s}$ at $64^{\circ} \mathrm{C}(P C F T)$ or $56^{\circ} \mathrm{C}(G A P D H)$ and $1 \mathrm{~min}$ at $72^{\circ} \mathrm{C}$ for thirty-five cycles. In the case of $R F C$ denaturation, annealing and elongation steps were carried out, respectively, for $30 \mathrm{~s}$ at $94^{\circ} \mathrm{C}, 30 \mathrm{~s}$ at $52 \cdot 1^{\circ} \mathrm{C}, 30 \mathrm{~s}$ at $72^{\circ} \mathrm{C}$ for thirty-five cycles. The final extension step was carried out for $10 \mathrm{~min}$ at $72^{\circ} \mathrm{C}$. The primers were designed using Primer3 Input (version 0.4.0; http://primer3.sourceforge.net). The sequences of the primers used were as follows: 5'-CATGCTAAGCGAACTGGTGA-3' (sense) and 5'-TTTCCACAGGACATGGACA-3' (antisense) for RFC, AAGCCAGTTATGGGCAACAC (sense) and GGATAGGCTGTGGTCAAGGA (antisense) for PCFT. The expected PCR products of size 120, 300 and $400 \mathrm{bp}$ were obtained for $\mathrm{r} R F C, \mathrm{r} P C F T$ and $\mathrm{r} G A P D H$, respectively when electrophoresed on $1.2 \%$ agarose gel. The densitometric analyses of products were determined by using 'Scion image' software (Scion Image, Frederick, MD, USA).

\section{Western blot analysis}

For protein expression studies, colon BLMV (100 $\mu \mathrm{g})$ were resolved on $10 \%$ SDS-PAGE and transferred to polyvinylidene fluoride membrane for $20 \mathrm{~min}$ at $15 \mathrm{~V}$. Western blotting was performed using the procedure described by Towbin et al. ${ }^{(24)}$ using polyclonal primary antibodies as rabbit anti-rat RFC (1:800 dilutions) raised against the specific region of rat RFC synthetic peptide corresponding to amino acids $494-512^{(25)}$. The polyclonal antibodies against PCFT (1:1000 dilutions) were raised against the specific region of rat PCFT synthetic peptide corresponding to amino acids 442-459. Secondary antibodies used were goat anti-rabbit IgG-horseradish peroxidase-labelled (1:20000 dilutions). The bands were visualised by either metal enhanced 3,3'-diaminodbenzidine substrate kit or enhanced chemiluminescence detection kit according to the manufacturer's instructions. The quantification of the blots was carried out by using 'Scion image'.

\section{Floatation on a discontinuous Optiprep density gradient}

Lipid rafts (LR) were isolated by floatation on Optiprep density gradient ${ }^{(26)}$ as described earlier ${ }^{(7)}$. Briefly, membrane preparations were centrifuged at $100000 \mathrm{~g}$ for $30 \mathrm{~min}$ at $4^{\circ} \mathrm{C}$ and then resuspended and incubated for $30 \mathrm{~min}$ at $4^{\circ} \mathrm{C}$ in TNE buffer containing $25 \mathrm{~mm}-$ Tris ( $\mathrm{pH} 7 \cdot 4$ ), $150 \mathrm{~mm}-\mathrm{NaCl}$, 5 mm-EDTA and $1 \%$ Triton X-100 supplemented with $1 \times$ complete protease inhibitor cocktail. The membranes were then adjusted to $40 \%$ final concentration of Optiprep and layered at the bottom of density gradient with steps of final concentrations of $35,30,25$ and $20 \%$ of Optiprep in TNE buffer. TNE buffer was laid on the top of the gradient, which was then centrifuged at $215000 \mathrm{~g}$ for $4 \mathrm{~h}$ at $4{ }^{\circ} \mathrm{C}$. Fractions were collected from the top of the gradient and then analysed by Western blotting. Proteins in the top four fractions are considered to be raft-associated ${ }^{(27)}$. Protein concentrations in each fraction were assessed by using better Bradford kit (Bio Basic Inc., East Markham, ON, Canada).

\section{Immunohistochemical analysis}

Freshly removed colon was cut followed by fixing in sufficient amount of $10 \%$ formalin $^{(28)}$. Paraffin sections of $4 \mu \mathrm{m}$ thickness on poly-L-lysine-coated slides were baked overnight at $37^{\circ} \mathrm{C}$. Endogenous peroxidase was quenched by pretreatment with $1 \% \mathrm{H}_{2} \mathrm{O}_{2}$ in methanol for 20 min followed by washings in PBS. Slides were put in primary diluted antibody (rabbit polyclonal anti-rat RFC and PCFT (1:200) for $2 \mathrm{~h}$ at $37^{\circ} \mathrm{C}$ followed by secondary antibodies as goat anti-rabbit IgG-horseradish peroxidase (1:200)). Presence of antibody at specific site(s) was revealed using freshly prepared $3,3^{\prime}$-diaminobenzene ${ }^{(29)}$ and $\mathrm{H}_{2} \mathrm{O}_{2}$ at room temperature for 3-5 min and counter-staining with haematoxylin.

\section{Estimation of folate by microbiological assay}

The folate estimations were determined by microtitre plate assay using $L$. casei as described earlier ${ }^{(18)}$. For intracellular folate concentrations in colon, a $10 \%$ homogenate of colon was made in phosphate buffer of $\mathrm{pH} 6.3$ containing $5 \mathrm{mg} / \mathrm{ml}$ ascorbate. The homogenate was incubated at $110^{\circ} \mathrm{C}$ for $10 \mathrm{~min}$ followed by centrifugation at $300 \mathrm{rpm}$ for $10 \mathrm{~min}$. Then, $0.1 \mathrm{ml}$ of the supernatant was treated with $0.02 \mathrm{ml}$ of rat plasma conjugase in $0.375 \mathrm{ml}$ of phosphate buffer of $\mathrm{pH}$ 4.5. The free folate was then determined by a standard microbiological microtitre plate assay using L. casei. All the steps were carried out in aseptic conditions.

\section{Statistical analysis}

The data were computed as means and standard deviations. Group means were compared by using the Student's $t$ test and ANOVA was used wherever necessary. The acceptable level of significance was less than $5 \%$ for each analysis. The power of the study was $0 \cdot 80$.

\section{Results}

\section{Folate levels in colon}

As the present study dealt with folate malabsorption during alcoholism, the determination of folate levels was of prime importance. The results showed that a significant reduction $(P<0.01)$ in colonic tissue folate levels (the levels were 8.8 (SD 0.09$)$ and $4.2(\mathrm{SD} 0.05) \mathrm{nmol} / \mathrm{g}$ tissue for control and ethanol fed, respectively) in chronic alcoholism, confirming the association of alcoholism with folate deficiency. 


\section{Kinetic characterisation of folate transport across colon} basolateral membrane

Folate uptake was studied at different time intervals from 10 to $240 \mathrm{~s}$, the uptake attained maximum value at $120 \mathrm{~s}$ in control and $240 \mathrm{~s}$ in ethanol-fed rats (Fig. 1(a)), with 14-23\% $(P<0.05,<0 \cdot 001)$ less folate uptake at different time intervals in ethanol-fed group as compared to control. Further, kinetic constants were determined in BLMV as a function of $5-\left[{ }^{14} \mathrm{C}\right]-$ methyltetrahydrofolate concentration varying from $0 \cdot 125$ to $8.0 \mu \mathrm{M}$ for $20 \mathrm{~s}$ (Fig. 2(a)). There was a gradual increase in folate uptake in the two groups of rats with increase in substrate concentration. In the ethanol-fed group, there was a significant reduction of $15-50 \%$ in uptake as compared to the control group at different concentrations of folate used. The data were then extrapolated as a Lineweaver-Burk plot and kinetic constants were determined (Fig. 2(b)). The $K_{\mathrm{m}}$ value in the ethanol-fed group was found to be 5.0 (SD 0.56) $\mu \mathrm{M}$ in comparison to 2.8 (SD 0.81) $\mu \mathrm{M}$ of control group $(P<0.01)$. In addition, $V_{\max }$ in control and ethanol-fed groups were 76.33 (SD 5.4) and 43.66 (SD 4.95) $\mathrm{pmol} / 30 \mathrm{~s}$ per $\mathrm{mg}$ protein $(P<0 \cdot 001)$, respectively.

To determine whether a proton gradient-dependent exchange process is involved in folate transport across the colon BLM, the effect of transmembrane $\mathrm{pH}$ was studied (Fig. 1(b)) keeping inside $\mathrm{pH}$ constant at $7 \cdot 4$. As the $\mathrm{pH}$ was increased in the extra-vesicular medium from 5.0 to $8 \cdot 0$, the uptake was constant till 6 , and started increasing beyond that, with maximum uptake at $\mathrm{pH} 7 \cdot 0$ in both the groups (Fig. 1(b)). In addition, a significant reduction of the order of $33-40 \%(P<0.01,<0.01,<0.001)$ in transport was observed in the ethanol-fed group at and above $\mathrm{pH} 7 \cdot 0$; however, no such uniform reduction was observed in the acidic $\mathrm{pH}$ range.

Further, in order to determine the specificity of the folate transporters (Fig. 2(c)), the folate transport was measured in the presence of the structural analogues methotrexate and unlabelled folic acid and inhibitors; thiamine pyrophosphate, reported to be a substrate of $\mathrm{RFC}^{(30)}$ and hemin, is a weak inhibitor of folate transport via heme carrier protein $1^{(6)}$. The structural analogues methotrexate and folic acid decreased the uptake by $41(P<0.001)$ and $44 \%(P<0 \cdot 01)$ in control, and $41(P<0.01)$ and $33 \%(P<0.05)$ in ethanol-fed rats, respectively, confirming the specificity of folate transporters. The inhibitor thiamine pyrophosphate significantly decreased the uptake by $20(P<0.05)$ and $38 \%(P<0.001)$ in control and ethanol-fed rats, respectively, while hemin did not change the uptake significantly.

To study the role of S-S groups (Fig. 2(d)), the effect of addition of dithiothreitol or Cleland's reagent on the transport of folate revealed decreased transport of folate by $56 \%$ $(P<0.01)$ in control and $32 \%$ in ethanol-fed rats $(P<0.01$; Fig. 2(d)). The determination of the influence of ATP on folate uptake showed that there was not any significant change in the uptake of folate across BLM in both the groups (Fig. 2(d)).

\section{Expression of the proton-coupled folate transporter and reduced folate carrier in colon; association with lipid rafts}

In order to elucidate the mechanism of reduced folate transport in chronic alcoholism, transcriptional and translation regulations of the RFC and PCFT were studied. The relative mRNA for the PCFT was approximately 1.8 fold (44\%) lower $(P<0.01)$ while that for the RFC was approximately 1.3 fold $(23 \%)$ lower $(P<0 \cdot 01)$ in the ethanol-fed group (Fig. 3(a) and (b))

Further, to investigate the effect of chronic alcohol feeding on the level of expression of the PCFT and the RFC protein, we performed Western blotting on the colon BLM protein of both the groups of rats (Fig. 3(c) and (d)). The results showed a significant decrease of 1.3 fold $(24 \%)$ in the level of expression of the PCFT $(P<0.05)$ and 2.3 fold $(57 \%)$ in the levels of RFC $(P<0 \cdot 01)$ proteins in ethanol-fed rats (Fig. 3).

LR are the specialised microdomains of the plasma membrane that are essential for the normal functioning of various membrane transporters ${ }^{(31-33)}$. We sought to determine whether the folate transporters (PCFT and RFC) are associated with lipid microdomains of the colon basolateral membrane of rat. We had validated this technique earlier by measuring the specific activity of alkaline phosphatase (well-known marker for LR) in all the fractions collected from gradient
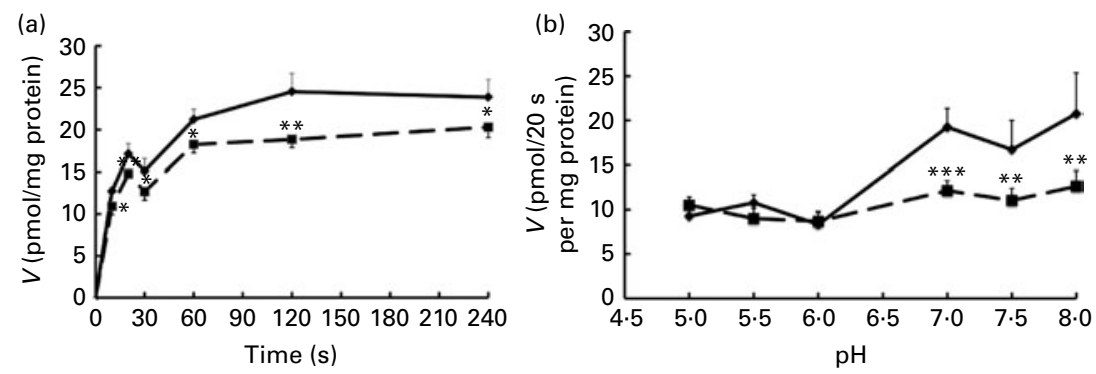

Fig. 1. (a) Time course of folate uptake in the colon basolateral membrane vesicles (BLMV). Uptake of $5-\left[{ }^{14} \mathrm{C}\right]-\mathrm{methyl}$-tetrahydrofuran (THF; $\left.0.5 \mu \mathrm{M}\right)$ was measured in a buffer of $\mathrm{pH} 7.0(100 \mathrm{~mm}-\mathrm{NaCl}, 80 \mathrm{~mm}-\mathrm{mannitol}, 10 \mathrm{~mm}-\mathrm{HEPES}, 10 \mathrm{~mm}-2-(\mathrm{N}$-morpholino)ethanesulfonic acid (MES), pH 7.0) for $10-240 \mathrm{~s}$. (b) Uptake of $5-\left[{ }^{14} \mathrm{C}\right]-$ methyl-THF in the colon BLMV as a function of $\mathrm{pH}$ optimum. Uptake was measured by varying the pH of incubation buffer (100 mM-NaCl, $80 \mathrm{~mm}$-mannitol, $10 \mathrm{~mm}$-HEPES, $10 \mathrm{~mm}$-MES) from 5.0 to 8.0 , keeping intravesicular $\mathrm{pH} 7.4$ at $0.5 \mu \mathrm{M}$ substrate concentration for $20 \mathrm{~s}$. Values are means and standard deviations of four separate uptake determinations. Mean values were significantly different from those of control $(\neg-)$ : ${ }^{\star} P<0.05$, ${ }^{\star \star} P<0.01$, ${ }^{\star \star \star} P<0.001$. $\rightarrow-$, Ethanol fed. 
(a)

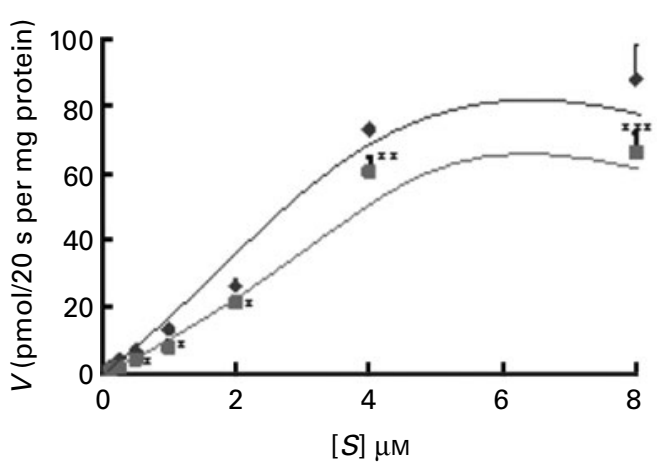

(c)

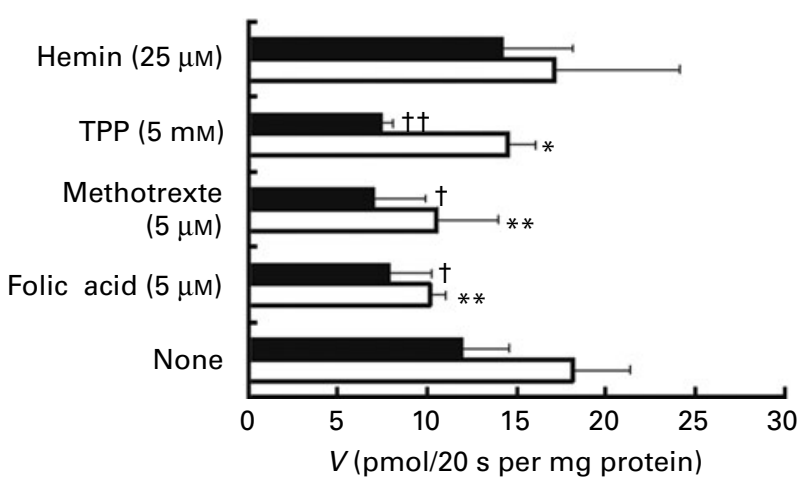

(b)

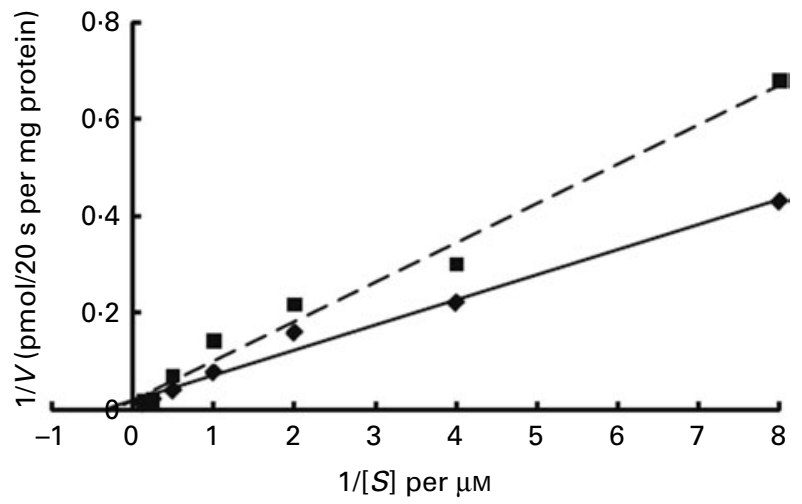

(d)

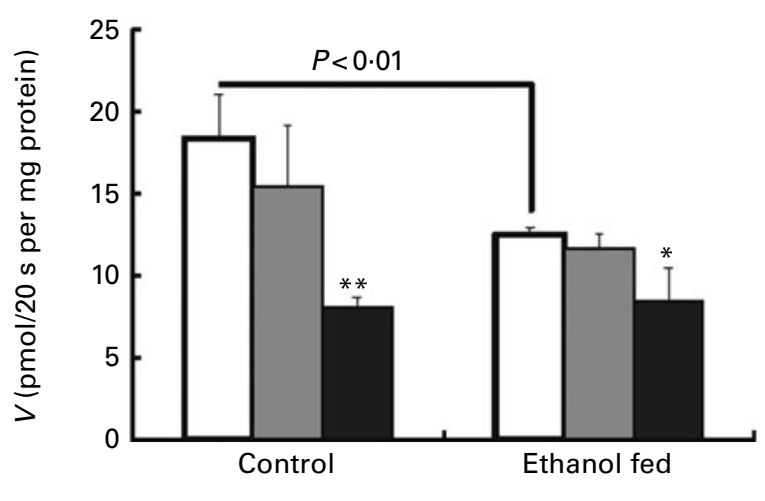

Fig. 2. (a) Uptake of $5-\left[{ }^{14} \mathrm{C}\right]-$ methyl-tetrahydrofuran (THF) in the colon basolateral membrane vesicles (BLMV) as a function of substrate concentration. Uptake was measured by varying $5-\left[{ }^{14} \mathrm{C}\right]-$ methyl-THF concentration from 0.125 to $8.0 \mu \mathrm{M}$ in the incubation buffer $(100 \mathrm{mM}-\mathrm{NaCl}, 80 \mathrm{mM}-\mathrm{mannitol}, 10 \mathrm{mM}-\mathrm{HEPES}, 10 \mathrm{mM}-$ 2-( $N$-morpholino)ethanesulfonic acid, $\mathrm{pH} 7.0)$ after incubating colon BLMV for $20 \mathrm{~s}$. $\$$, Control; $\mathbf{n}$, ethanol fed. Mean values were significantly different from those of control: ${ }^{\star} P<0.05,{ }^{\star \star} P<0.01,{ }^{\star \star \star} P<0.001$. (b) Lineweaver-Burk plot at $\mathrm{pH} 7.0$. ${ }^{\star}$, Control; $\boldsymbol{\square}$, ethanol fed. (c) Effect of structural analogue and inhibitors on the uptake of 5 - $\left[{ }^{14} \mathrm{C}\right]$-methyl-THF in the colon BLMV. Uptake of $5-\left[{ }^{14} \mathrm{C}\right]-$ methyl-THF $(0.5 \mu \mathrm{M})$ was measured with and without analogue $(5 \mu \mathrm{M}$-folic acid and $5 \mu \mathrm{M}$ methotrexate)/inhibitor (5 mM-thymine pyrophosphate (TPP) and $25 \mu \mathrm{M}$-hemin) in incubation buffer of $\mathrm{pH} 7 \cdot 0$. $\square$, Control; $\mathbf{\square}$, ethanol fed. (d) Uptake of 5-[ $\left.{ }^{14} \mathrm{C}\right]-$ methyl-THF was determined in the presence of $S-S$ group reacting reagent (1 mM-dithiothreitol ( $\square$ )) and in the presence of 1 mM-ATP ( $\square$ ). $\square$, None. Values are means and standard deviations represented of four separate uptake determinations, carried out in duplicate. Mean values were significantly different from those of none in control: ${ }^{*} P<0.05,{ }^{* *} P<0.01$. Mean values significantly different from those of none in ethanol fed: $\dagger P<0.05, \dagger \dagger P<0.01$.

using $\mathrm{CAM}^{(7)}$. The pattern of specific activity of alkaline phosphatase in all these fractions had revealed a gradient with considerable activity in the top floating fractions ${ }^{(1-4)}$, indicating that these fractions contained LR. So the top fractions isolated from the gradient using colon BLM were subjected to Western blotting for the PCFT and the RFC (Fig. 3(e) and (h)). We found the presence of the PCFT and RFC protein in the floating fractions on the top five fractions (20-30\%) with negligible or no expression thereafter of Optiprep density gradient. Together, these data provide strong evidence that the majority of the PCFT and the RFC pool are associated with the lipid raft microdomains. Moreover, chronic alcoholism leads to a decreased association of both the PCFT and the RFC to the LR (Fig. 3(e) and (h)). The extent of decrease was 1.23- to 1.41 -fold for PCFT $(P<0.01$ and $<0.05)$ and $1 \cdot 12$ - to $1 \cdot 21$-fold for RFC $(P<0.01$, $<0.05)$, respectively, which is in accordance with the decreased levels of these transporters in the colon BLM.

\section{Localisation of proton-coupled folate transporter and reduced folate carrier in colon}

As there was a significant decrease in RFC and PCFT expression across colon BLM, we studied the localisation of these transporters in colon by immunohistochemistry (Fig. 4). The localisation of the RFC and PCFT was seen at both the apical and basolateral side membranes of colon. In ethanolfed rats, there was marked reduction in the intensity of RFC and PCFT positive cells in colon (Fig. 4).

\section{Discussion}

The observed reduced folate levels in the colon of ethanol-fed rats suggested the association of chronic alcoholism with colonic folate malabsorption. After the transport of folate across the CAM, the folate is transported across colon BLM to portal circulation. The higher values of $K_{\mathrm{m}}(5.0$ (SD 0.56$) \mu \mathrm{M}$ in comparison to $2.8(\mathrm{SD} 0.81) \mu \mathrm{M}$ of the control group 
(a)

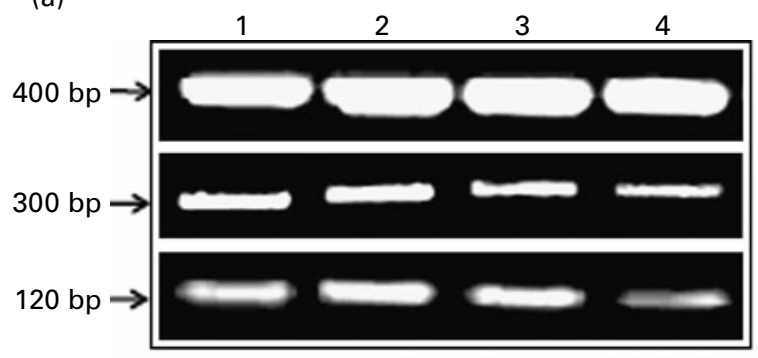

(b)

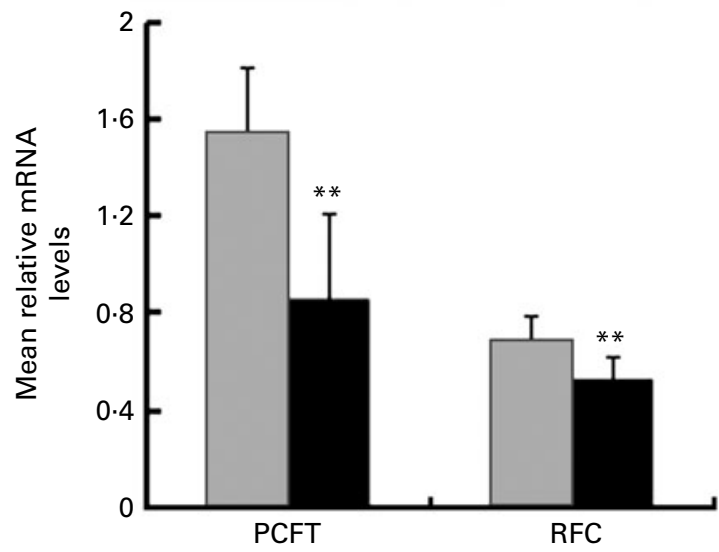

(e)

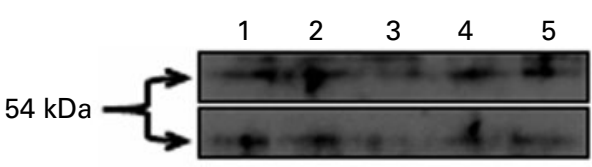

(f)

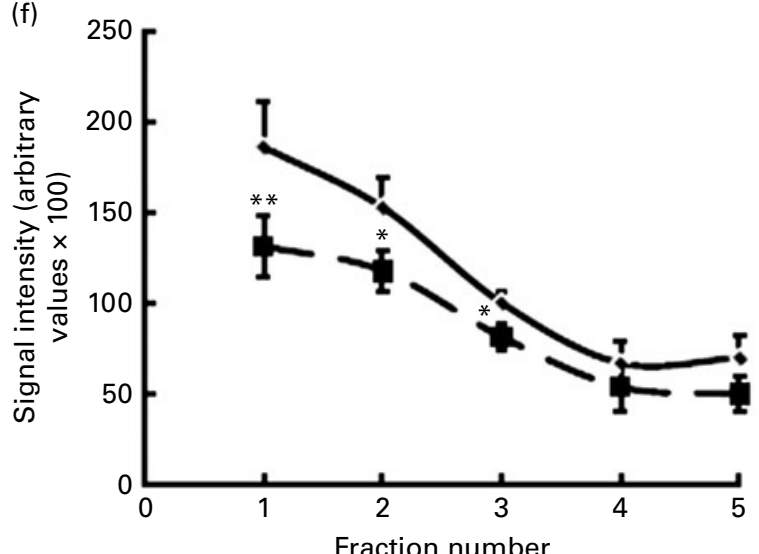

(c)

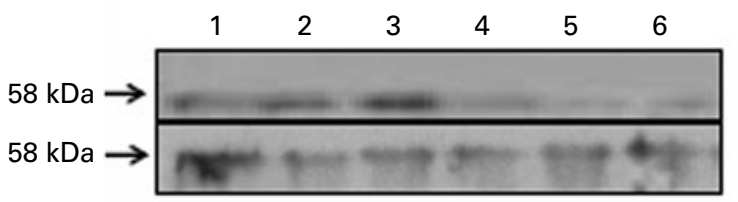

(d)

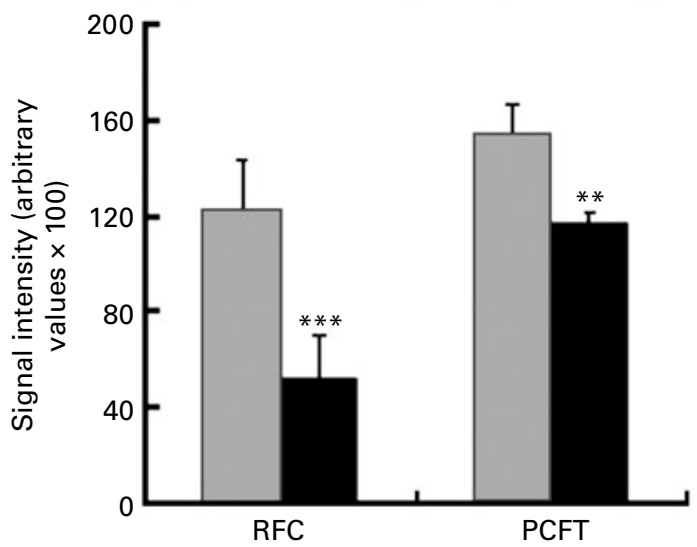

(g)

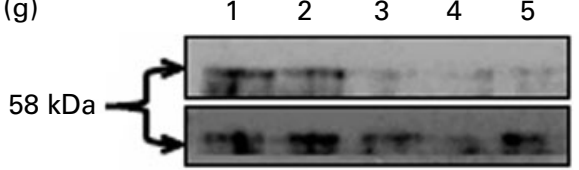

(h)

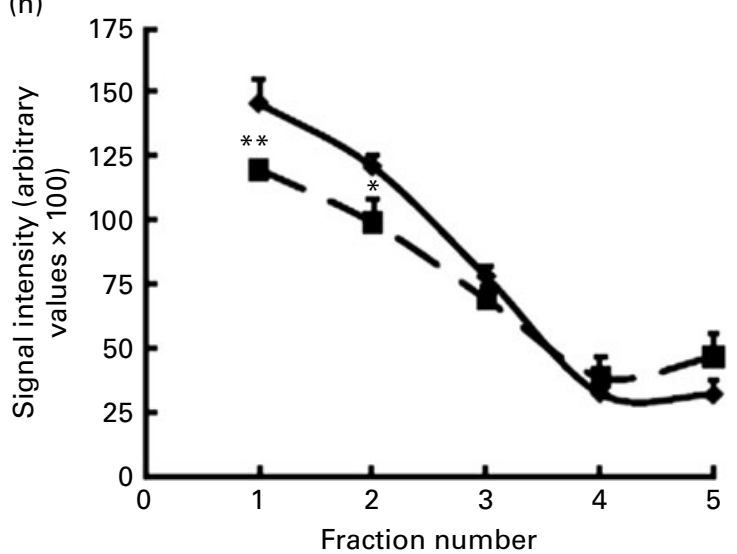

Fig. 3. (a) RT-PCR analysis of reduced folate carrier $(R F C)$ and proton-coupled folate transporter (PCFT) with glyceraldehyde 3-phosphate dehydrogenase as an internal control in colon. Resolved on 1.2\% agarose gel electrophoresis, lanes 1 and 2: control; 3 and 4: ethanol fed. (b) Densitometric analysis representing relative change in PCFT and RFC mRNA expression. Values are means and standard deviations of five separate set of experiments. Mean values were significantly different from those of control: ${ }^{* \star} P<0.01$. $\square$, Control; $\mathbf{\square}$, ethanol fed. (c) Western blot analysis of colon basolateral membrane (BLM) using anti RFC (58 kDa), anti-PCFT (54 kDa) antibodies, lane 1-3: control; 4-6: ethanol fed. (d) Graph represents summary data of densitometric analysis. $\square$, Control; $\square$, ethanol fed. Mean values were significantly different from those of control: ${ }^{* \star} P<0.01$, ${ }^{* * *} P<0.001$. (e and g) Association of folate transporters (PCFT and RFC) proteins with lipid rafts in colon BLM. The colon BLM were subjected to floatation on Optiprep density gradients, and fractions were collected from top of the gradients (fractions 1-4 represent detergent-resistant membrane). Fractions were separated by electrophoresis and analysed by Western blotting using (e) anti-PCFT ( $54 \mathrm{kDa}$ ) and (g) RFC (58 kDa) antibodies. The representive blot shown for PCFT and RFC expression as, upper panel lane 1--5: control; lower panel lane 1-5: ethanol fed. $(f$ and $h$ ) Blots were scanned, and the intensity of bands was determined by densitometric analysis. Values are means and standard deviations of four separate experiments. Mean values were significantly different from those of control $(\neg-)$ : ${ }^{*} P<0.05{ }^{* \star} P<0.01$. $-\square-$, Ethanol fed. 
(a)

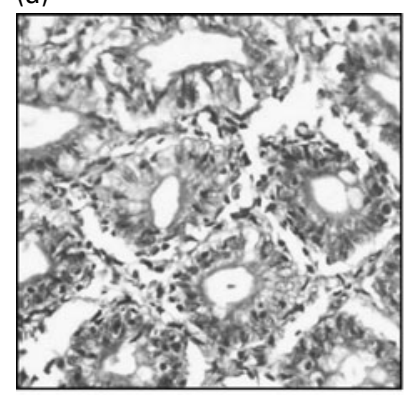

(c)

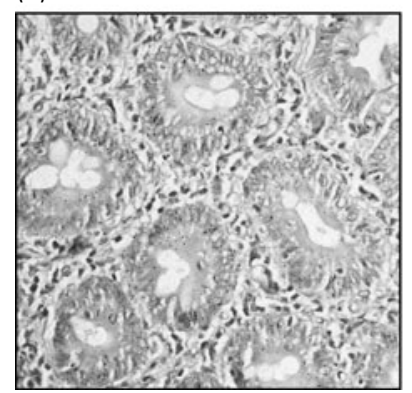

(b)

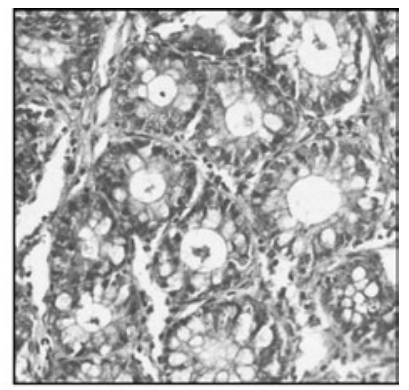

(d)

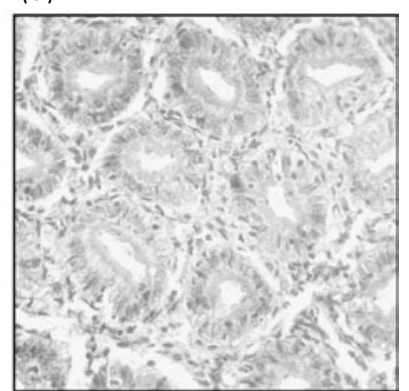

Fig. 4. Immunohistochemical analysis of colon sections exposed to anti-proton coupled folate transporter (PCFT) and anti-reduced folate carrier (RFC) antibodies showing relative localisation of ( $a$ and $b$ ) PCFT (control and ethanol fed) and (c and d) RFC (control and ethanol fed) protein. Figures $(20 \times)$ shown are representative of each group.

$(P<0 \cdot 01)$ and decreased $V_{\max }$ in ethanol-fed rats suggested that the folate exit across the BLM occurs less efficiently in chronic alcoholism and thus can reflect its lower availability in portal circulation. Also, a higher value of $K_{\mathrm{m}}$, i.e. $2 \cdot 8$ (SD $0 \cdot 81) \mu \mathrm{M}$ of colon BLM $v \cdot 1.42$ (SD 0.13) $\mu \mathrm{M}$ of intestinal BLM, and 1.5 (SD 0.19) of the $\mathrm{CAM}^{(7,22)}$ suggested that the transport of folate across colon BLM occurs less efficiently as compared to intestinal BLM and CAM.

In order to determine the chemical driving force for the uphill folate transport, the neutral/alkaline $\mathrm{pH}$ was found to be the energising force in the BLM. The results depicted that neither the inwardly nor the outwardly directed $\mathrm{H}^{+}$gradient is responsible for the folate uptake, as maximum folate uptake was observed at $\mathrm{pH} 7 \cdot 4$ inside and 7.0-7.4 outside $\mathrm{pH}$, supporting the earlier observations, which suggests that folate transport across colon basolateral membrane occurs at neutral $\mathrm{pH}^{(11)}$ and displayed similar characteristics as of intestinal $\mathrm{BLM}^{(22)}$. Moreover, for the evaluation of the specificity of the folate transport system, structural analogues significantly inhibited the folate uptake. Less decrease in the folate transport in the presence of structural analogues methotrexate and unlabelled folic acid might be due to less affinity of the folate transporters to these substrates as compared to 5-methyltetrahydrofolate. The presence of thiamine pyrophosphate significantly reduced the folate transport across the BLM while the hemin did not change the uptake significantly. This suggested that the RFC was the main transporter involved in the folate exit across colon basolateral membrane, supporting the earlier contention which suggests that folate uptake via RFC is tissue specific ${ }^{(34)}$ and PCFT shows maximum transport

activity at acidic $\mathrm{pH}^{(6,35)}$. This again supports the earlier results which showed maximum uptake at alkaline neutral $\mathrm{pH}$, which is characteristic of folate uptake by RFC, confirming the results that neutral $\mathrm{pH}$ is the characteristic of folate uptake across the colon BLM, as RFC transport folate in neutral $\mathrm{pH}^{(6,35,36)}$. Moreover, the folate uptake in BLM was sensitive to $\mathrm{S}-\mathrm{S}$ group, suggesting that $\mathrm{S}-\mathrm{S}$ bond(s) in its intact form is (are) required for the transport activity of folate transporters and the transport was found to be energy-independent and the transport was not mediated by ATP-binding cassette transporters, as there was no significant change in activity of folate transport in the presence of ATP.

The decreased $V_{\max }$ of folate uptake process observed in ethanol-fed rats could relate to the reduced number of PCFT and RFC molecules on the colon BLM. In this context, the observed down-regulation (Fig. 3(a)-(d)) in the PCFT and the RFC mRNA corresponds to the reduced protein expression at colon BLM in ethanol-fed rats. This decrease in folate uptake in association with the down-regulation of the folate transporters in the rat colon is similar to the results of our earlier studies carried out in the small intestine ${ }^{(16,18)}$ and kidneys ${ }^{(37,38)}$, and might contribute to ethanol-induced folate deficiency. Moreover, the decreased folate content of colon tissue in ethanol-fed rats reflects reduced substrate availability for the transporters at the BLM under in vivo conditions and might also contribute to the colonic malabsorption in chronic alcoholism. Although we have observed a reduced folate transport across the colonic BLM in ethanol-fed rats, a substantial amount of uptake still takes place during chronic alcoholism. This might be due to the associated passive diffusion component of the transport process along with the carriermediated transport. An earlier study ${ }^{(39)}$ carried out in L1210 leukaemia cells has shown that $20 \%$ of the total methotrexate uptake was contributed by passive diffusion; whether ethanol feeding affects this passive diffusion of 5-methyltetrahydrofolate under our experimental set is not known and is yet to be determined.

In the plane of basolateral membranes, LR could act as platforms modulating the protein activity by accumulating active pools of the transporters ${ }^{(31)}$. Proteins might enter LR at the golgi level and their shuttling between the golgi and cell membranes allows the cells to exert regulatory control over the surface expression of their proteins. Utilising the Optiprep floatation, we found that folate transporter proteins - PCFT and RFC - were present in the floating fractions corresponding to lipid raft microdomains of colon basolateral membranes. Our findings demonstrated the presence of PCFT and RFC in LR of the colon membranes of rats, which might be due to alteration in the lipid composition of biological membranes by alcohol ${ }^{(40)}$.

The immunohistochemical localisation of colon shows the localisation of both the folate transporters to the BBM as well as in the basolateral membrane surfaces, confirming the immunoblot experiment which demonstrated the expression of PCFT and RFC on both the BBM and BLM of colon. Moreover, less staining in the case of ethanol-fed rats suggests the decreased expression of PCFT and RFC. 


\section{Conclusions}

In conclusion, these findings demonstrate that the decreased colon folate transport in chronic alcoholism may be attributed to decreased affinity and the number of folate transporter molecules across the colon BLM surfaces. Folate transport is carrier-mediated saturable, energy-independent, $\mathrm{pH}$-dependent with the major involvement of RFC in folate exit across colon basolateral membrane with minimal involvement from PCFT. The decrease in uptake was associated with down-regulation of folate transporters and lipid raft associated reduction in levels of these transporters in colon BLM. The consequence of reduced folate transport across CAM results in reduced folate levels in colon.

\section{Acknowledgements}

The present study was supported by the financial grant sanctioned to J. K. from Council of Scientific and Industrial Research, New Delhi, India. N. A. W. carried out the animal study, transport study, prepared BLMV from animals for gene expression analyses, Western blotting and performed the statistical analysis and helped in the writing of the manuscript. A. H. carried out RT-PCR, Western blotting. K. L. K. was instrumental in designing the experiments involving radioisotopes and provided the facility for carrying out radioassays. $\mathrm{J}$. K. conceived the study and participated in its design and coordination. The authors declare that there are no potential conflicts of interest. All the authors read and approved the final manuscript.

\section{References}

1. Wani NA, Hamid A \& Kaur J (2008) Folate status in various pathophysiological conditions. IUBMB Life 60, 834-842.

2. Zhao R, Matherly LH \& Goldman ID (2009) Membrane transporters and folate homeostasis: intestinal absorption and transport into systemic compartments and tissues. Expert Rev Mol Med 11, e4.

3. Choi SW \& Mason JB (2002) Folate status: effects on pathways of colorectal carcinogenesis. J Nutr 132, 2413S-2418S.

4. Kim YI (1999) Folate and carcinogenesis: evidence, mechanisms, and implications. J Nutr Biochem 10, 66-88.

5. Kim YI (2003) Role of folate in colon cancer development and progression. J Nutr 133, 3731S-3739S.

6. Qiu A, Jansen M, Sakaris A, et al. (2006) Identification of an intestinal folate transporter and the molecular basis for hereditary folate malabsorption. Cell 127, 917-928.

7. Wani NA \& Kaur J (2011) Reduced levels of folate transporters (PCFT and RFC) in membrane lipid rafts result in colonic folate malabsorption in chronic alcoholism. J Cell Physiol 226, 579-587.

8. Nguyen TT, Dyer DL, Dunning DD, et al. (1997) Human intestinal folate transport: cloning, expression, and distribution of complementary RNA. Gastroenterology $\mathbf{1 1 2}$, $783-791$.

9. Hamid A, Wani NA \& Kaur J (2009) New perspectives on folate transport in relation to alcoholism-induced folate malabsorption - association with epigenome stability and cancer development. FEBS J 276, 2175-2191.

10. Egan MG, Sirlin S, Rumberger BG, et al. (1995) Rapid decline in folylpolyglutamate synthetase activity and gene expression during maturation of HL-60 cells. Nature of the effect, impact on folate compound polyglutamate pools, and evidence for programmed down-regulation during maturation. J Biol Chem 270, 5462-5468.

11. Dudeja PK, Kode A, Alnounou M, et al. (2001) Mechanism of folate transport across the human colonic basolateral membrane. Am J Physiol Gastrointest Liver Physiol 281, G54-G60.

12. Sakuta H \& Suzuki $T$ (2005) Alcohol consumption and plasma homocysteine. Alcohol 37, 73-77.

13. Hamid A \& Kaur J (2009) Role of signaling pathways in the regulation of folate transport in ethanol-fed rats. $J$ Nutr Biochem 20, 291-297.

14. Bode C \& Bode JC (2003) Effect of alcohol consumption on the gut. Best Pract Res Clin Gastroenterol 17, 575-592.

15. De Marco P, Calevo MG, Moroni A, et al. (2003) Reduced folate carrier polymorphism $(80 \mathrm{~A} \rightarrow \mathrm{G})$ and neural tube defects. Eur J Hum Genet 11, 245-252.

16. Hamid A, Kaur J \& Mahmood A (2007) Evaluation of the kinetic properties of the folate transport system in intestinal absorptive epithelium during experimental ethanol ingestion. Mol Cell Biochem 304, 265-271.

17. Hamid A \& Kaur J (2007) Long-term alcohol ingestion alters the folate-binding kinetics in intestinal brush border membrane in experimental alcoholism. Alcohol 41, 441-446.

18. Hamid A, Wani NA, Rana S, et al. (2007) Down-regulation of reduced folate carrier may result in folate malabsorption across intestinal brush border membrane during experimental alcoholism. FEBS J 274, 6317-6328.

19. McMartin KE (1984) Increased urinary folate excretion and decreased plasma folate levels in the rat after acute ethanol treatment. Alcohol Clin Exp Res 8, 172-178.

20. McMartin KE \& Collins TD (1983) Relationship of alcohol metabolism to folate deficiency produced by ethanol in the rat. Pharmacol Biochem Behav 18, Suppl. 1, 257-262.

21. Scalera V, Storelli C, Storelli-Joss C, et al. (1980) A simple and fast method for the isolation of basolateral plasma membranes from rat small-intestinal epithelial cells. Biochem $J$ 186, 177-181

22. Hamid A, Kiran M, Rana S, et al. (2009) Low folate transport across intestinal basolateral surface is associated with downregulation of reduced folate carrier in in vivo model of folate malabsorption. IUBMB Life 61, 236-243.

23. Dev S, Ahmad Wani N \& Kaur J (2011) Regulatory mechanisms of intestinal folate uptake in a rat model of folate oversupplementation. Br J Nutr 105, 827-835.

24. Towbin H, Staehelin T \& Gordon J (1992) Electrophoretic transfer of proteins from polyacrylamide gels to nitrocellulose sheets: procedure and some applications. 1979. Biotechnology 24, 145-149.

25. Said HM, Chatterjee N, Haq RU, et al. (2000) Adaptive regulation of intestinal folate uptake: effect of dietary folate deficiency. Am J Physiol Cell Physiol 279, C1889-C1895.

26. Hanwell D, Ishikawa T, Saleki R, et al. (2002) Trafficking and cell surface stability of the epithelial $\mathrm{Na}^{+}$channel expressed in epithelial Madin-Darby canine kidney cells. J Biol Chem 277, 9772-9779.

27. Oliferenko S, Paiha K, Harder T, et al. (1999) Analysis of CD44-containing lipid rafts: recruitment of annexin II and stabilization by the actin cytoskeleton. J Cell Biol 146, 843-854.

28. Zhang Y, Shao JS, Xie QM, et al. (1996) Immunolocalization of alkaline phosphatase and surfactant-like particle proteins in rat duodenum during fat absorption. Gastroenterology 110, 478-488 
29. Sobierajska K, Glos J, Daborowska J, et al. (2010) Visualization of the interaction between Gbetagamma and tubulin during light-induced cell elongation of Blepharisma japonicum. Photochem Photobiol Sci 9, 1101-1110.

30. Zhao R, Gao F, Wang Y, et al. (2001) Impact of the reduced folate carrier on the accumulation of active thiamin metabolites in murine leukemia cells. I Biol Chem 276 1114-1118.

31. Anderson RG \& Jacobson K (2002) A role for lipid shells in targeting proteins to caveolae, rafts, and other lipid domains. Science 296, 1821-1825.

32. Simons K \& Toomre D (2000) Lipid rafts and signal transduction. Nat Rev Mol Cell Biol 1, 31-39.

33. Annaba F, Sarwar Z, Kumar P, et al. (2008) Modulation of ileal bile acid transporter (ASBT) activity by depletion of plasma membrane cholesterol: association with lipid rafts. Am I Physiol Gastrointest Liver Physiol 294, G489-G497.

34. Kumar CK, Nguyen TT, Gonzales FB, et al. (1998) Comparison of intestinal folate carrier clone expressed in IEC-6 cells and in Xenopus oocytes. Am J Physiol 274, C289-C294.
35. Inoue K, Nakai Y, Ueda S, et al. (2008) Functional characterization of PCFT/HCP1 as the molecular entity of the carriermediated intestinal folate transport system in the rat model. Am I Physiol Gastrointest Liver Physiol 294, G660-G668.

36. Zhao R, Qiu A, Tsai E, et al. (2008) The proton-coupled folate transporter: impact on pemetrexed transport and on antifolates activities compared with the reduced folate carrier. Mol Pharmacol 74, 854-862.

37. Hamid A \& Kaur J (2006) Chronic alcoholism alters the transport characteristics of folate in rat renal brush border membrane. Alcohol 38, 59-66.

38. Hamid A \& Kaur J (2005) Kinetic characteristics of folate binding to rat renal brush border membrane in chronic alcoholism. Mol Cell Biochem 280, 219-225.

39. Yang CH, Peterson RH, Sirotnak FM, et al. (1979) Folate analog transport by plasma membrane vesicles isolated from L1210 leukemia cells. J Biol Chem 254, 1402-1407.

40. Kaur M, Kaur J, Gupta R, et al. (2004) Ethanol-induced changes in lipid composition of intestinal microvillus membrane in rats fed different dietary fats. Ann Nutr Metab $\mathbf{4 8}$, $221-227$. 